\title{
FORUM
}

\section{Trait-based paradise - about the importance of real functionality}

\author{
R. Gallé $e^{1,2}$ and P. Batáry ${ }^{1}$ \\ ${ }^{1}$ MTA Centre for Ecological Research, Institute of Ecology and Botany, Lendület Landscape and Conservation Ecology \\ ${ }^{2}$ Corresponding author: Alkotmány u. 2-4, 2163 Vácrátót, Hungary. Tel.: +36-38-360122. \\ E-mail: galle.robert@okologia.mta.hu
}

Keywords: Body size; Functional diversity; Trait classification .

Abstract: We briefly complement Endrédi et al. (2019) forum paper from terrestrial animal ecological points of view. We discuss the origins of trait-based approach, challenges of trait classifications, and we provide an example of a commonly used trait, body size.

\section{Introduction}

Endrédi et al. (2018) in their forum paper about traitbased paradise called the attention to the relationship between the biological knowledge and the methodological issues related to trait-based ecological analyses. We largely share their views, and aimed to complement it here from terrestrial animal ecological points of view with the following points discussed below: 1) the shift from species-based to traitbased concept; 2) (functional) traits have been always used in ecology, i.e. there is nothing new under the sun ("nihil novi sub sole"); 3.) challenges of trait classifications; 4.) problem around one of most common trait, body size.

Over the last decade, there has been an obvious shift from species-based approaches towards a trait-based concept in community ecology (Moretti et al. 2017). On the one hand, numerous studies showed that increasing species richness and diversity can enhance ecosystem functioning (Cardinale et al. 2012), however, large part of the variation may remain unexplained. On the other hand, other studies, such as by Kleijn et al. (2015), argued somewhat against this insurance hypothesis, and showed that in agroecosystems only a handful, but dominant species deliver the pollination of crops. Nevertheless, the trait-based concept allows ecologists to directly include biologically important information in statistical models. Furthermore, it helps information sharing and generalization by reducing the taxon and ecosystem dependency of the results (Endrédi et al. 2018). McGill et al. (2006) suggested a paradigm shift that the main focus of community ecology should be given to functional traits.

However, the use of trait-based information in ecology goes back to the early decades of $20^{\text {th }}$ century, i.e. to the dawn of this scientific field - for example Elton (1927), emphasized the functional role of species in a community e.g. in his niche concept. Later, Balogh's "syntrophium" (1953), Root's "guild" (1967) and the "functional group concept" (Cummins 1974,) were the foundations of the recently used feeding traits. The use of trait-based information has grown exponentially over the last twenty years, which improves our understanding of ecosystem processes. Additionally, numerous recent studies use this information as a proxy for ecosystem functioning (Gagic et al. 2015). However ecologically meaningful traits must be chosen carefully according to the research question considering the scale of the study and the interactions between populations to properly describe the ecological processes driving ecosystem functioning (Moles 2018, Rosado et al. 2016). Functional traits that are irrelevant for the research question may blur the differences in functionally relevant traits or even produce false conclusions (Dehling and Stouffer 2018).

Traits are usually categorized to "response traits", which measure the response of an organism to environmental change, and "effect traits", which determine the effect of an organism on ecosystem functioning (Lavorel and Garnier 2002) and also refer to interactions between species (Dehling and Stouffer, 2018). However, this categorization is not always straightforward. For example, body size of an invertebrate is influenced by numerous factors e.g. food availability or temperature (Merckx et al. 2018), and it may also affect several ecosystem functions such as pollination and predation. Hodgson et al. (1999) suggested the categorization to "hard traits", which are functionally important, but their measurement is labour intensive, expensive or time consuming, and to "soft" traits, which are easily measurable, but usually only a proxy of a functionally important trait. The above mentioned body size is among the most easily measured traits, such basic morphological information is usually available for a wide range of organisms, including invertebrates, at least for the adult stadium. 
However, body size is usually used as a proxy for a hardly measurable functional trait (McGill et al. 2006). It has been known for a long time that size influences predator-prey interactions (Yodzis and Innes 1992), and physiological rates (Calder 1984). The positive correlation between body size and dispersal ability has been shown for numerous active disperser taxa, e.g. butterflies (Sekar, 2012), ground-dwelling carabids (Gutiérrez and Menéndez, 1997) and spiders (Pedley and Dolman, 2014). Jenkins et al. (2007) demonstrated that the positive correlation does not stand for passive dispersers, for example body size of ballooning spiders is negatively correlated with dispersal ability (Bell et al. 2005). Furthermore, the incorporation of pollutants is more rapid for small-sized animals due to higher metabolic rates than large sized animals (Blaum et al. 2011). However, in their meta-analysis, Zvereva and Kozlov (2010) found, that pollution has a severe effect on larger arthropod predators due to accumulation of pollutants, thus pollution may even favour small-bodied herbivore populations by creating an enemy-free space.

Another contradictory example of the use of body size was recently published in Nature by Merckx et al. (2018) about their urban ecological study. They convincingly used it as a proxy for both metabolic cost (urban-heat-island effect drive shifts toward smaller body sizes) and for mobility (highly fragmented urban areas drive shifts toward larger body sizes).

The trait-based concept is ready for use with numerous well-established indices and procedures available to quantify functional diversity. However, databases of functionally important traits, especially of less studied invertebrate taxa, are scarce and usually incomplete (Moretti et al. 2017). Besides theoretical improvement and formation of new hypotheses, a great progress would be the development of such trait databases according to standardized protocols across taxa.

Acknowledgements: We are grateful to L. Gallé for valuable comments on the manuscript. RG was supported by the National Research, Development and Innovation Office-NKFIH (NKFI FK 131379). PB was supported by the Economic Development and Innovation Operational Programme of Hungary (GINOP-2.3.2-15-2016-00019). R.G. was supported by the János Bolyai Research Scholarship of the Hungarian Academy of Sciences.

\section{References}

Balogh, J. 1953. Zoocönologia alapjai - Grundzüge der Zoozönologie. Akadémiai Kiadó, Budapest.

Bell, J.R., D.A. Bohan, E.M. Shaw and G.S. Weyman. 2005 Ballooning dispersal using silk: World fauna, phylogenies, genetics and models. Bull. Entomol. Res. 95:69-114.

Blaum, N., E. Mosner, M. Schwager and F. Jeltsch. 2011. How functional is functional? Ecological groupings in terrestrial animal ecology: towards an animal functional type approach. Biodiv. Cons. 20:2333-2345.

Calder, W.A.I. 1984. Size, Function, and Life History. Courier Corporation, Dover.
Cardinale, B.J., J.E. Duffy, A. Gonzalez, D.U. Hooper, C. Perrings, P. Venail, A. Narwani, G.M., Mace, D. Tilman, D.A.Wardle, A.P. Kinzig, G.C. Daily, M. Loreau, J.B. Grace, A. Larigauderie, D.S. Srivastava and S. Naeem. 2012. Biodiversity loss and its impact on humanity. Nature 486:59-67.

Cummins, K.W. 1974. Structure and function of stream ecosystems. BioScience 24:631-641.

Dehling, D.M., and D.B. Stouffer. 2018. Bringing the Eltonian niche into functional diversity. Oikos 127:1711-1723.

Elton, C.S. 1927. Animal Ecology. Sidgwick and Jackson, London, UK.

Endrédi, A., F. Jordán and A. Abonyi. 2018. Trait-based paradiseor only feeding the computer with biology? Community Ecol. 19:319-321.

Gagic, V., I. Bartomeus, T. Jonsson, A. Taylor, C. Winqvist, C. Fischer, E.M. Slade, I. Steffan-Dewenter, M. Emmerson, S.G. Potts, T. Tscharntke, W. Weisser and R. Bommarco. 2015. Functional identity and diversity of animals predict ecosystem functioning better than species-based indices. Proc. R. Soc. London B Biol. Sci. 282:1801.

Gutiérrez, D. and R. Menéndez. 1997. Patterns in the distribution, abundance and body size of carabid beetles (Coleoptera: Caraboidea) in relation to dispersal ability. J. Biogeogr. 24:903-914.

Hodgson, J. G., P.J. Wilson, R. Hunt, J.P. Grime and K. Thompson. 1999. Allocating CSR plant functional types: a soft approach to a hard problem. Oikos 85:282-294.

Jenkins, D.G., C.R. Brescacin, C.V. Duxbury, J.A. Elliott, J.A. Evans, K.R. Grablow, M. Hillegass, B.N. Lyon, G.A. Metzger, M.L. Olandese, D. Pepe, G.A. Silvers, H.N. Suresch, T.N. Thompson, C.M. Trexler, G.E. Williams, N.C. Williams and S.E. Williams. 2007. Does size matter for dispersal distance? Global Ecol. Biogeogr. 16:415-425.

Kleijn, D., R. Winfree, I. Bartomeus, L.G. Carvalheiro, M. Henry, R. Isaacs, A.-M. Klein, C. Kremen, L.K. M'Gonigle, R. Rader, T.H. Ricketts, N.M. Williams, N. Lee Adamson, J.S. Ascher, A. Báldi, P. Batáry, F. Benjamin, J.C. Biesmeijer, E.J. Blitzer, R. Bommarco, M. R. Brand, V. Bretagnolle, L., Button, D.P. Cariveau, R. Chifflet, J.F. Colville, B.N. Danforth, E. Elle, M.P.D. Garratt, F. Herzog, A. Holzschuh, B.G. Howlett, F. Jauker, S. Jha, E. Knop, K.M. Krewenka, V. Le Féon, Y. Mandelik, E.A. May, M.G. Park, G. Pisanty, M. Reemer, V. Riedinger, O. Rollin, M. Rundlof, H.S. Sardinas, J. Scheper, A.R. Sciligo, H.G. Smit, I. Steffan-Dewenter, R. Thorp, T. Tscharntke, J. Verhulst, B.F. Viana, B.E. Vaissiére, R. Veldtman, C. Westphal and S.G. Pott. 2015. Delivery of crop pollination services is an insufficient argument for wild pollinator conservation. Nat. Commun. 6:7414.

Lavorel, S., and É Garnier. 2002. Predicting changes in community composition and ecosystem functioning from plant traits: revisiting the Holy Grail. Funct. Ecol. 16:545-556.

McGill, B.J., B.J. Enquist, E. Weiher and M. Westoby. 2006 Rebuilding community ecology from functional traits. Trends Ecol. Evol. 21:178-185.

Merckx T, C. Souffreau, A. Kaiser, L. F. Baardsen, T. Backeljau, D. Bonte, K. I. Brans, M. Cours, M. Dahirel, N. Debortoli, K. de Wolf, J.M.T. Engelen, D. Fontaneto, A.T. Gianuca, L. Govaert, F. Hendrickx, J. Higuti, L. Lens, K. Martens, H. Matheve, E. Matthysen, E. Piano, R. Sablon, I. Schön, K. van Doninck, L. de Meester and H. van Dyck. 2018. Body size shifts in aquatic and terrestrial urban communities. Nature 558:113-116.

Moles, A. T. 2018. Being John Harper: Using evolutionary ideas to improve understanding of global patterns in plant traits. J. Ecol. 106:1-18. 
Moretti, M., A.T.C. Dias, F. de Bello, F. Altermatt, S.L. Chown, F.M. Azcarate, J.R. Bell, B. Fournier, M. Hedde, J. Hortal, S. Ibanez, E. Öckinger, J.P. Sousa, J. Ellers and M.P. Berg. 2017. Handbook of protocols for standardized measurement of terrestrial invertebrate functional traits. Funct. Ecol. 31:558-567.

Pedley, S.M. and P.M. Dolman. 2014. Multi-taxa trait and functional responses to physical disturbance. J. Anim. Ecol. 83:1542-1552.

Root, R.B. 1967. The niche exploitation pattern of the blue-gray gnatcatcher. Ecol. Monogr. 37:317-350.

Rosado, B.H., M.S. Figueiredo, E.A. de Mattos and C.E. Grelle. 2016. Eltonian shortfall due to the Grinnellian view: functional ecology between the mismatch of niche concepts. Ecography 39:1034-1041.

Sekar, S. 2012. A meta-analysis of the traits affecting dispersal ability in butterflies: can wingspan be used as a proxy? J. Anim. Ecol. 81:174-184.
Yodzis, P. and S. Innes. 1992: Body size and consumer-resource dynamics. Am. Nat. 139:115-1175.

Zvereva, E.L. and M.V. Kozlov. 2010. Responses of terrestrial arthropods to air pollution: a meta-analysis. Environ. Sci. Pollut. R. 17:297-311.

Received January 18, 2019 Revised May 24, 2019

Accepted October 16, 2019

Open Access statement. This is an open-access article distributed under the terms of the Creative Commons Attribution-NonCommercial 4.0 International License (https://creativecommons.org/licenses/by-nc/4.0/), which permits unrestricted use, distribution, and reproduction in any medium for non-commercial purposes, provided the original author and source are credited, a link to the CC License is provided, and changes - if any - are indicated. 